NASA Technical Memorandum 102472

ICOMP-89-32

\title{
Probabilistic Modeling for Simulation of Aerodynamic Uncertainties in Propulsion Systems
}

Awatef Hamed

University of Cincinnati

Cincinnati, Ohio

and Institute for Computational Mechanics in Propulsion

Lewis Research Center.

Cleveland, Ohio

(NASA-TM-10P472) PROPADILISTTC MODFLING FOR SIMULATIUN TF AERTOYNAMIC UNCERTAINTIFS IN

POOPULSION SYSTFMS (NASA) 280 CSCL $21 \mathrm{~F}$
$N 90-21036$

Hets

Unclas

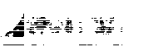

December 1989

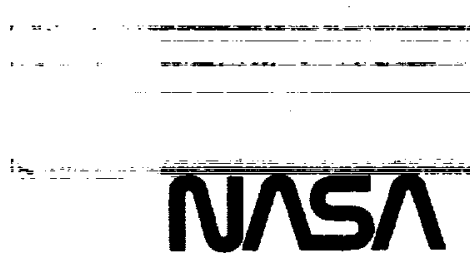


PROBABILISTIC MODELING FOR SIMULATION OF AERODYNAMIC UNCERTAINTIES

IN PROPULSION SYSTEMS

\author{
Awatef Hamed ${ }^{*}$ \\ Department of Aerospace Engineering \& Engineering Mechanics \\ University of Cincinnati \\ Cincinnati, $\mathrm{OH} 45221$ \\ and Institute for Computational Mechanics in Propulsion \\ Lewis Research Center \\ Cleveland, $\mathrm{OH} 44135$
}

ABSTRACT

The focus of this work was to explore the numerical simulation of the probabilistic aerothermodynamic response of propulsion system components to randomness in their environment. The reusable rocket engine turbopumps were selected as an example because of the severe cryogenic environment in which they operate. The thermal and combustion instabilities, coupled with the engine thrust requirements from start up to shut down, lead to randomness in the flow variables and uncertainties in the aerodynamic loading.

The probabilistic modeling of the turbopumps aerodynamic response was accomplished using the panel method coupled with Fast Probability Integration methods. The aerodynamic response in the form of probabilistic rotor blades and splitter loading were predicted and the results presented for specified flow coefficient and rotor preswirl variance. Possible future applications of the aerothermodynamic probabilistic modeling in engine transient simulation, condition monitoring and engine life prediction are briefly discussed.

\footnotetext{
*Work funded by Space Act Agreement C-99066-G.
} 


\section{INTRODUCTION}

Traditional engineering design and/or analysis procedures are deterministic in nature. The uncertainties in the load definition, material properties and component characteristics are handled in these designs through safety factors. Recently, a major effort was initiated by the NASA Lewis Research Center under the PSAM (Probabilistic Structural Analysis Methods) program to develop analytical and numerical techniques for predicting the probabilistic response of the structural components [1]. This new approach makes it now possible to assess the risk of failure inherent in a given design and to identify the design features affecting risk [2]. Examples of the application of this new methodology to propulsion system components can be found in reference [3].

The purpose of this work is to explore the use of probabilistic modeling techniques in predicting the aerothermodynamic response of propulsion system components to randomness in their environment. The randomness in the flow variables and the associated uncertainties in a component's aerothermodynamic performance can be a consequence of combustion instabilities, thermal cycling and/or the engine built variance. A probabilistic flow analysis was used to predict the aerodynamic performance parameters in the form of distribution functions, for specified variance in the component's environment. The analysis was also used to investigate the sensitivity of the aerodynamic response to the various parameters. The results obtained from the probabilistic determination of the SSME high pressure turbopump performance are presented, and their possible use in condition monitoring, design optimization and ultimately life prediction are discussed. 


\section{OVERVIEW OF PROBABILISTIC SIMULATION METHODOLOGY}

The purpose of probabilistic modeling is to simulate the effect of variability in a propulsion system environment on the performance of its components. The random variables are those with a certain amount of statistical uncertainty. In the case of turbomachines, they might include the incoming flow conditions, the rotational speed, the turbomachinery blade configuration or other parameters which can affect the performance. The simulation of the corresponding variation in the performance requires an analysis based on probabilities. The aerodynamic response of the system can be expressed as a function of the random variables as follows:

$$
\bar{Y}=f(\bar{x})
$$

where $\bar{Y}$ is the vector of response variables and $\bar{x}$ is the vector of random variables. Random variables may be characterized experimentally or theoretically in terms of distribution models. Experimental measurements from a number of tests may give a set of data points which are scattered over a certain range. The characterization of these variables based on experimental results can be depicted in a histogram, in which each block size represents the number of occurrences within a small range. The probability density function, or the smooth curve representing the scatter in the data, can be obtained from a sufficiently large number of tests. This can easily be simulated using a statistical package, to determine the best analytical fit for data distribution (normal, log normal, Weibul, etc.). For example the best statistical representation for the data of Fig. 1 representing the measured SSME high pressure turbopump RPM at 100\% RPL (rated power level), was found to be a normal distribution with a mean value of 34,133 and a standard deviation of 210 . 
The response variable $Y$, which is a function of random variables, will have its own probability density and cumulative distribution functions. Numerical methods are often used to obtain solutions to equation (1), since the multiple integrals in the solution can be evaluated analytically only if the function $f(x)$ is linear, the random variables are normal and their number is restricted. In addition, the functional relationship of equation (1) is usually not given in a closed form but rather at a discrete number of points from a deterministic flow solution.

Several computational approaches have been considered to evaluate the probabilistic response in the PSAM program including the Monte Carlo Simulation, the method of moments and the fast probability integration methods. A discussion of the capabilities of these methods and examples involving comparison of the results of their applications to sample problems with a small number of random variables, can be found in reference [4]. The FPI fast probability integration code developed under PSAM was used in the present study, since it is generally applicable when the relationship between the response variable and the primary variables is not given in a closed form. It is based on constructing an analytical approximation (polynomial) for the performance function and using a modified Newton iteration scheme to compute the perturbed solutions about a mean state [4]. This approach was demonstrated to have high accuracy with respect to the Monte Carlo simulation and required less computational effort [4], and to exhibit good convergence properties for small changes about the deterministic solution at the expansion point [5]. 


\section{PROCEDURE}

For a given propulsion system or component, it is necessary to first identify the uncertainties in its environment that can affect its aerothermodynamic performance. The probabilistic aerodynamic response to the associated variance in the appropriate parameters is then computed. The determination of the probabilistic aerodynamic response requires probabilistic tools as well as a deterministic aerodynamics code. The appropriate choice of the latter will depend on the particular component, the simulated flow phenomena and the aerodynamic response parameters of interest. It can be a viscous or inviscid code for unsteady or steady, three dimensional or other reduced levels of approximating the flow field in the propulsion system. The FPI method was used in the probabilistic analysis of the deterministic solutions obtained for the different specified values of the random variables.

\section{SSME TURBOPUMPS}

The SSME reusable high performance rocket engines operate in a severe environment over a range of variable thrust. The engine thrust requirements from start-up to full power steady loading is followed by throttling to 60 70 percent thrust and then to full power before shut down, all occurring within about 450 seconds (Fig. 2). The thermal loading and combustion instabilities in the complex flow environment lead to randomness in the performance parameters and uncertainties in the component's loading. Since the turbopumps of the SSME operate in environments that are more severe and uncertain than in other noncryogenic turbomachinery applications, they were identified as primary candidates for developing probabilistic aerodynamic models. The probabilistic results are presented for the high pressure fuel 
turbopump. The same methodology can be used to predict the probabilistic aerodynamic response of other propulsion system components after the proper identification of the sources of randomness in their environment and of the appropriate analytical and numerical methods for each particular application.

\section{OPERATING ENVIRONMENT}

The SSME is controlled by an on-board computer which monitors the engine's vital functions, performs engine throttling and initiates shutdown procedures in the event that redline parameters are violated. The engine data handled are identified by PI's (parameter identification number) and stored in the Command and Data Simulator System (CADS). Figures 3a and $3 \mathrm{~b}$ from reference [6] show the variation in some of the engine's performance parameters with the power level over the 0.65 to 1.09 RPL range. The mean value of the various parameters can be seen clearly in the figures, as well as an indication of their variance. The variance in some of the performance parameters at the 0.65 and $1.09 \mathrm{RPL}$ is better illustrated in Figs. 4 through 9. These test data can be used to generate probability density functions and to determine the type of variance and standard deviation for the corresponding parameters using statistical tools. The mean values of the flow inlet parameters and the pump's rotational speed were taken according to Rocketdyne's power balance model [7].

The random variables, those with uncertainties that can affect the turbopump performance include the flow inlet conditions $\left(P_{t}, T_{t}\right)$, the mass flow rate and the rotational speed. For simplicity, the geometric configuration was not included in the present study. When expressed in 
dimensionless parameters, the performance of turbomachines can generally be shown to be dependent on a reduced number of variables. In the case of incompressible flow in the punp rotor, two parameters affect the performance of its rotor, namely the flow coefficient, $\mathrm{C}_{\mathrm{x}} / \mathrm{U}$ (which is directly related to the mass flow), and the flow preswirl parameter, $\mathrm{C}_{\mathrm{u}} / \mathrm{U}$. A simple derivation based on the turbine's Euler equation can show the linear relationship between the specific work or head and these two parameters. The response variables presented in the results are the nondimensional axial and circumferential blade forces.

\section{$\underline{\text { RESULTS }}$}

Figure 10 shows the high pressure turbopump blade geometry at the tip, with three splitter blades in each blade-to-blade passage. The presented results for the flow field were obtained using the PANEL code [8] because of its ability to handle multibody configurations with good resolution at the blade leading edges.

Table 1 lists the performance parameters at 90\% RPL according to reference [7]. These were used as the mean values in the present probabilistic flow analysis. The computed blade surface pressure distribution at the mean values of the parameters are presented in Figs. 11 through 14.

The probabilistic flow analysis results were obtained using the FPI code. They are presented in the form of cumulative distribution functions, $\mathrm{CDF}$, for the dimensionless axial and tangential blade loading, in response to specified variance in the flow coefficient, $C_{x} / N$, and the preswirl parameter, $\mathrm{C}_{\mathrm{u}} / \mathrm{U}$. The sensitivity, $\mathrm{S}$, of the computed blade loading to the 
two primary random variables $\left(\mathrm{C}_{\mathrm{x}} / \mathrm{U}, \mathrm{C}_{\mathrm{u}} / \mathrm{U}\right)$ were also computed. They are identified as $S\left(C_{x} / U\right)$ and $S\left(C_{u} / U\right)$ in Figs. 15 through 24 , which also shows the cumulative distribution function, $C D F$, for the blade loading. Two types of flow coefficient and preswirl variance were considered a normal distribution and a $\log$ norm (Table 2). Figures 15 through 18 present the results obtained for the normal distribution with $10 \%$ standard deviation. The computed probabilistic aerodynamic results for a $\log$ normal $C_{x} / U, C_{u} / U$ distribution with $5 \%$ standard deviation are presented in Figs. 19 through 22. Some of the results for a normal distribution with $5 \%$ standard deviation are presented in Figs. 23 and 24. Comparing Figs. 19a with 23 and 22 with 24 , one can see that both the aerodynamic response and its sensitivity to $C_{x} / U, C_{u} / U$ are almost the same for the log norm and normal distribution. Table 3 summarizes the probabilistic aerodynamic response results of Figs. 15 through 24 . The sensitivity analysis results shown in the figures indicate that the blade loading sensitivities to the preswirl $\mathrm{C}_{\mathrm{u}} / \mathrm{U}$ and to the flow coefficient $\mathrm{C}_{\mathrm{x}} / \mathrm{U}$ are of the same order of magnitude. As the blade loading increases, the sensitivity to $C_{\mathrm{u}} / \mathrm{U}$ increases and to $\mathrm{C}_{\mathrm{x}} / \mathrm{U}$ decreases in most cases. The probabilistic axial loading of the first blade and its sensitivities need further investigation because of the difficulties encountered in its FPI analysis.

\section{DISCUSSIONS}

The effect of changing the flow coefficient and preswirl on the blades aerodynamic loadings are listed in Table 4 and presented in Figs. 25 and 26. These figures confirm the linear relationship between the blade loading and 
both random variables over a range of $\pm 10 \%$ variation in $C_{x} / U$ and $C_{u} / U$. This makes it possible to evaluate analytically the probability distribution function of the response variables for the case of normal distribution of the variance in the two random variables. Such a procedure is recommended for assessing the accuracy and evaluating the range of perturbations over which the FPI results are within the desired accuracy. In general, more than two random (primitive) variables affect the steady state performance of turbomachines in the case of compressible flow. The engine transient performance is affected by an even larger number of random variables [9] in which case the analysis can become more complex, and the probabilistic results more difficult to assess.

\section{CONCLUSIONS}

One possible application of the presented turbopump's probabilistic aerodynamic response is to assess the uncertainties in the SSME internal axial loads. According to reference [10], the large axial loads (100's $\mathrm{k}$ lbf levels) mandates axial load analyses at all SSME operating modes to ensure the adequacy of the balancing piston and bearing designs. This will require an integration of the axial blade loadings over each blade surface area at the different operating conditions. While the presented dimensionless blade loading results only depend on two parameters, the actual blade loading is affected by the dynamic head (based on the relative velocity) and the blade area. Additional uncertainties can be introduced by these parameters as can be seen from the measured variance in the inlet total flow properties of Figs. 5, 6, 8 and 9 . Such a probabilistic axial loading analysis can be accomplished by expanding the scope of the present 
exploratory investigation with more computational efforts to simulate the probabilistic blade loading distribution over the SSME's operating range.

\section{RECOMMENDATIONS}

In general, the results of a probabilistic aerodynamic analysis can be used in the definition of the aerodynamic loads in structural analysis. For such an application, it is recommended that additional parameters, such as variance in the individual blade geometries, be included in the simulation. Presently, the probabilistic simulation already accomplished in the PSAM program include material properties, blade characteristics and mechanical loading, but the aerodynamic loads have not been defined probabilistically. However, under steady state conditions, the aerodynamic loadings are generally very small compared to centrifugal loading and to the thermal stresses in internally cooled blades [11]. The author's own experience [9] suggests that the probabilistic modeling of the system's transient aerodynamic response would produce more dramatic results. Such an analysis can be very useful for predicting probabilistic engine responses including turbopumps, surge and cavitation based on measured or deduced variance in the important performance parameters. The results of a probabilistic aerothermodynamic analysis can also be very useful in failure and life prediction [12]. In particular, the thermal shock transients in the rocket engines can have a strong impact on the life of its components. Results showing the complex steady state aerothermodynamic flow fields in the SSME turbines were presented in reference [13]. A probabilistic aerothermodynamic analysis would provide valuable information on the thermal blade loading and its impact on life. Condition monitoring is an area in which the probabilistic aerothermodynamic modeling can find applications. A 
conveniently measureable flow property can be Identified as a monitoring candidate based on the sensitivity results of the probabilistic aerodynamics analysis. A probabilistic analysis will make it possible to take into consideration the variance in the monitored response with engine built. Finally, design optimization studies can be based on the probabilistic aerodynamic results, with a better definition of the uncertainties than in current deterministic methods.

\section{REFERENCES}

1. Nagpal, V.K., Rubinstein, R. and Chamis, C.C., "Probabilistic Structural Analysis to Quantify Uncertainties Associated with Turbopump Blades," NASA TM 100278, February 1988.

2. Cruse, T.A., "Designing for an Uncertain World," Aerospace America, November 1988 , pp. 36-39.

3. Chamis, C.C., "Probabilistic Structural Analysis Methods for Space Propulsion System Components," NASA TM 88861, June 1986.

4. Burnsick, O.H., "Probabilistic Structural Analysis for Space Propulsion System Components," Advances in Aerospace Structural Analysis, AD-09 (Proceedings of Symposium on Probabilistic Design and Analysis, WAM ASME, Miami, FL, November 1985.

5. Dias, J.B. and Nagtegaal, J.C., "Efficient Algorithms for Use in Probabilistic Finite Element Analysis," Advances in Aerospace Structural Analysis, AD-09 (Proceedings of Symposium on Probabilistic Design and Analysis, WAM ASME, Miami, FL, November 1985.

6. Storms, J., "SSME Phase II - Engine Performance Prediction," IL 85-129-251, September 1985 . 
7. Ngugen, D.G., "Engine Balance and Dynamic Mode1," RSS 3598-1, Vol. I, November 1974, Rocketdyne Division, Rockwell International.

8. McFarland, E.R., "A FORTRAN Computer Code for Calculating Flows in Multiple-Blade-Element Cascades," NASA TM 87104, November 1985.

9. Sugiyama, 0., Tabakoff, W. and Hamed, A., "J85 Surge Transient Simulation," Journal of Propulsion and Power, Vo1. 5, No. 3, May-June 1989, pp. $375-381$.

10. Creare, G.A., Rose11o, A.R. and Fetfatsides, A.K., "SSME Alternate Turbopump (Pump Section) Axial Load Analysis," AIAA 89-2607, July 1989.

11. Hamed, A., Sheoran, Y., and Tabakoff, W., "Stress Analysis Study in Cooled Radial Inflow Turbines," Journal of Aircraft, December 1978, pp. $803-804$.

12. Cassenti, B., "Time Dependent Probabilistic Failure of Coated Components," AIAA 89-2900, July 1989.

13. Civinskas, K.C., Boyle, R.J. and McConnaughey, H.V., "Impact of ETO Propellants on the Aerothermodynamic Analysis of Propulsion Components," AIAA Paper 88-3091, July 1988.

14. Butas, J., NASA Marshal1, Private Communication. 

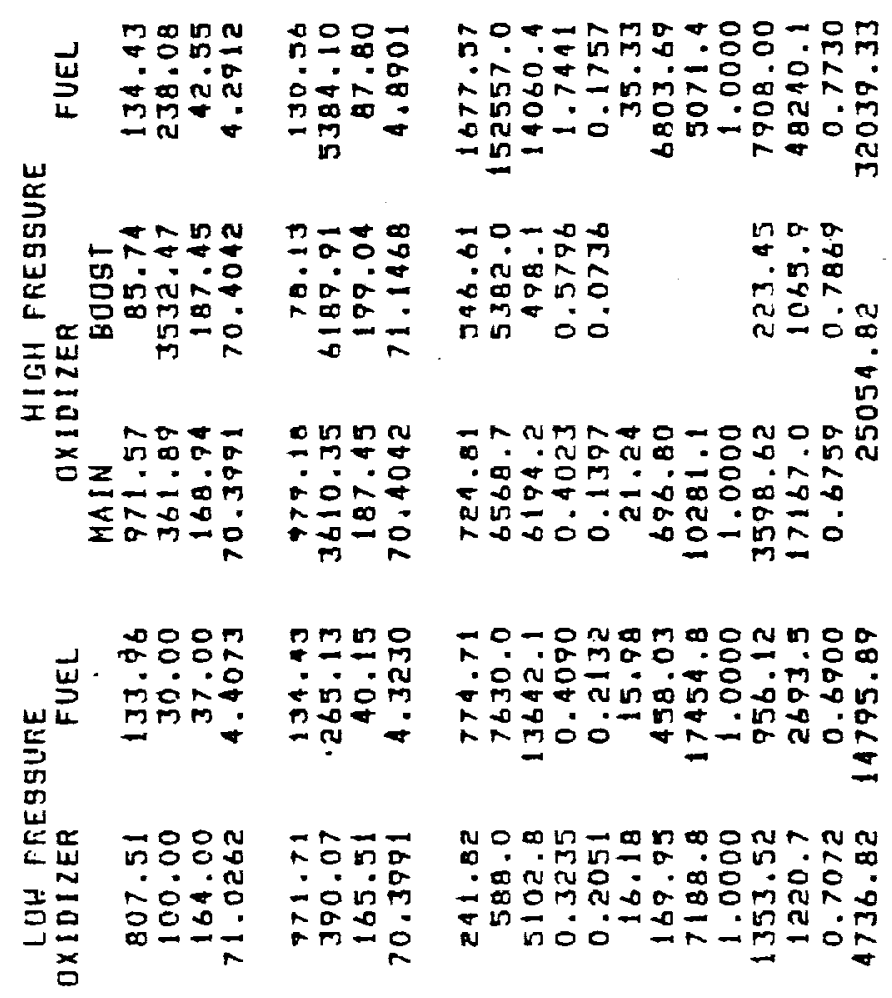

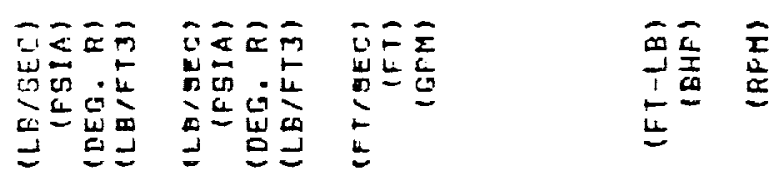

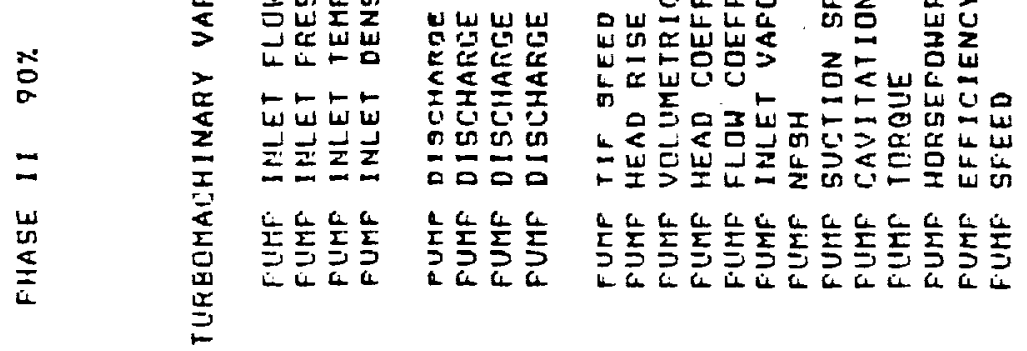


TABLE 2

RANDOM VARIABLES

HPFP AT 90\% RPL

\begin{tabular}{ccccccc}
\hline Cases & \multicolumn{3}{c}{$\mathrm{C}_{\mathrm{x}} / \mathrm{U}$} & & \multicolumn{3}{c}{$\mathrm{C}_{\mathrm{u}} / \mathrm{U}$} & \\
& Distribution & $\begin{array}{l}\text { Mean } \\
\text { Value }\end{array}$ & $\begin{array}{l}\text { Standard } \\
\text { Deviation }\end{array}$ & Distribution & $\begin{array}{l}\text { Mean } \\
\text { Value }\end{array}$ & $\begin{array}{l}\text { Standard } \\
\text { Deviation }\end{array}$ \\
\hline 1 & norma1 & 0.2467 & $10 \%$ & normal & 0.293 & $10 \%$ \\
2 & $\log$ normal & 0.2467 & $5 \%$ & log normal & 0.293 & $5 \%$ \\
3 & norma1 & 0.2467 & $5 \%$ & normal & 0.293 & $5 \%$ \\
\hline
\end{tabular}


TABLE 3

PROBABILISTIC AERODYNAMIC RESPONSE OF

THE SSME HPTP BLADES AT THE TIP

\begin{tabular}{|c|c|c|c|c|c|c|}
\hline \multirow{2}{*}{$\begin{array}{l}\text { Blade } \\
\text { Loading }\end{array}$} & \multicolumn{2}{|c|}{ Case 1} & \multicolumn{2}{|c|}{ Case 2} & \multicolumn{2}{|c|}{ Case 3} \\
\hline & $\begin{array}{l}\text { Mean } \\
\text { Value }\end{array}$ & $\begin{array}{l}\text { Standard } \\
\text { Deviation }\end{array}$ & $\begin{array}{l}\text { Mean } \\
\text { Value }\end{array}$ & $\begin{array}{l}\text { Standard } \\
\text { Deviation }\end{array}$ & $\begin{array}{l}\text { Mean } \\
\text { Value }\end{array}$ & $\begin{array}{l}\text { Standard } \\
\text { Deviation }\end{array}$ \\
\hline$F_{t 1}$ & 0.5292 & 0.0306 & 0.5275 & 0.01595 & 0.5275 & 0.01595 \\
\hline $\mathrm{F}_{\mathrm{al}}$ & - & $\cdots$ & 0.8945 & 0.0971 & 0.8945 & 0.0971 \\
\hline$F_{t 2}$ & 0.4610 & 0.0506 & 0.4565 & 0.0263 & 0.4565 & 0.0263 \\
\hline $\mathrm{F}_{\mathrm{a} 2}$ & 0.5175 & 0.0550 & 0.5666 & 0.0292 & 0.5666 & 0.0292 \\
\hline$F_{t 3}$ & 0.4320 & 0.0454 & 0.4275 & 0.02375 & 0.4275 & 0.02375 \\
\hline $\mathrm{F}_{\mathrm{a} 3}$ & 0.6545 & 0.0541 & 0.6500 & 0.0283 & 0.6500 & 0.0283 \\
\hline$F_{t 4}$ & 0.4985 & 0.0584 & 0.4918 & 0.0303 & 0.4918 & 0.0303 \\
\hline $\mathrm{F}_{\mathrm{a} 4}$ & 0.63175 & 0.0663 & 0.6255 & 0.0346 & 0.6255 & 0.0346 \\
\hline
\end{tabular}

Cases correspond to those of Table 2 . 
TABLE 4

EFFECT OF $c_{x} / N$ AND $c_{u} / U$ ON BLADE LOADING

\begin{tabular}{lllllllllll}
\hline & $\mathrm{C}_{\mathrm{x}} / \mathrm{U}$ & $\mathrm{C}_{\mathrm{u}} / \mathrm{U}$ & $\mathrm{F}_{\mathrm{t} 1}$ & $\mathrm{~F}_{\mathrm{a} 1}$ & $\mathrm{~F}_{\mathrm{t} 2}$ & $\mathrm{~F}_{\mathrm{a} 2}$ & $\mathrm{~F}_{t 3}$ & $\mathrm{~F}_{\mathrm{a} 3}$ & $\mathrm{~F}_{t 4}$ & $\mathrm{~F}_{\mathrm{a} 4}$ \\
\hline 1 & 0.2467 & 0.293 & 0.528 & 0.898 & 0.455 & 0.566 & 0.427 & 0.649 & 0.491 & 0.624 \\
2 & 0.222 & 0.293 & 0.501 & 0.889 & 0.413 & 0.521 & 0.39 & 0.607 & 0.441 & 0.568 \\
3 & 0.2344 & 0.293 & 0.517 & 0.898 & 0.435 & 0.544 & 0.409 & 0.63 & 0.4666 & 0.597 \\
4 & 0.259 & 0.293 & 0.538 & 0.894 & 0.476 & 0.588 & 0.445 & 0.668 & 0.516 & 0.652 \\
5 & 0.2714 & 0.293 & 0.554 & 0.9005 & 0.503 & 0.617 & 0.4685 & 0.6952 & 0.5475 & 0.6805 \\
6 & 0.2467 & 0.264 & 0.541 & 0.936 & 0.458 & 0.569 & 0.427 & 0.654 & 0.492 & 0.6275 \\
7 & 0.2467 & 0.278 & 0.516 & 0.887 & 0.4395 & 0.5474 & 0.412 & 0.629 & 0.474 & 0.604 \\
8 & 0.2467 & 0.308 & 0.54 & 0.906 & 0.4725 & 0.5858 & 0.443 & 0.671 & 0.509 & 0.646 \\
9 & 0.2467 & 0.322 & 0.514 & 0.854 & 0.456 & 0.563 & 0.428 & 0.645 & 0.493 & 0.621 \\
\hline
\end{tabular}

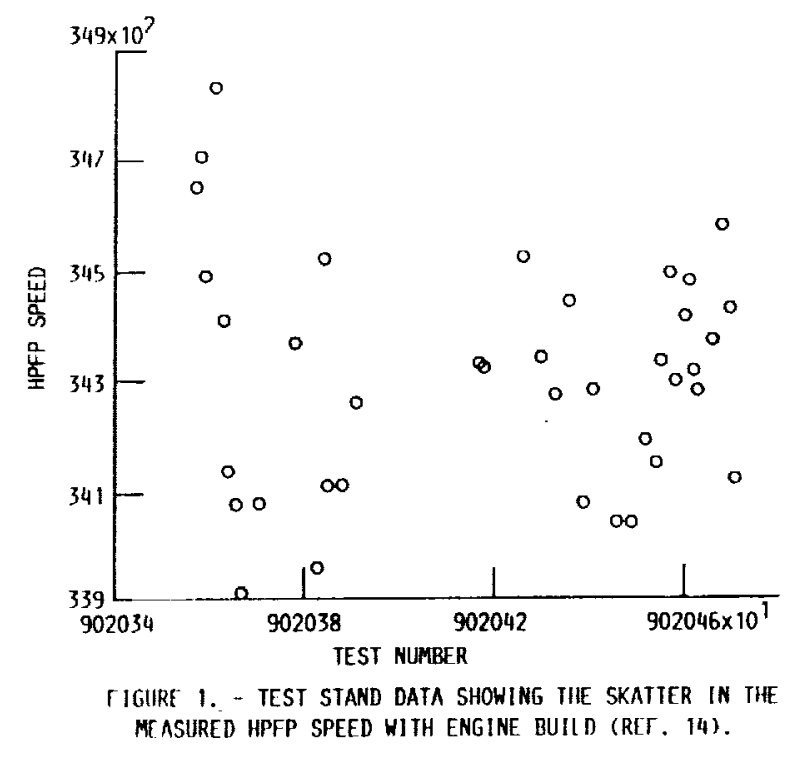




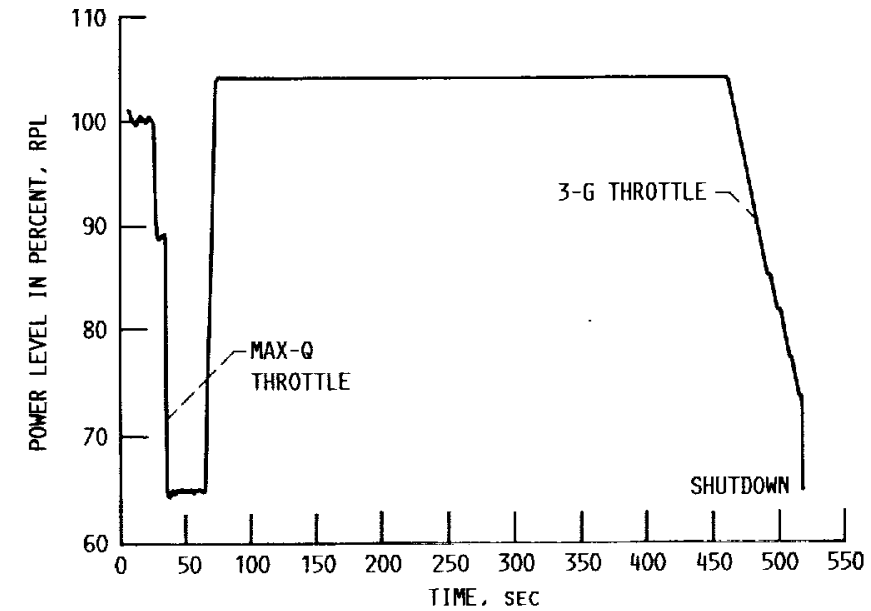

FIgURE 2. - TYPICAL SPACE SHUTTLE MAIN ENGINE 104 PERCENT MISSION.

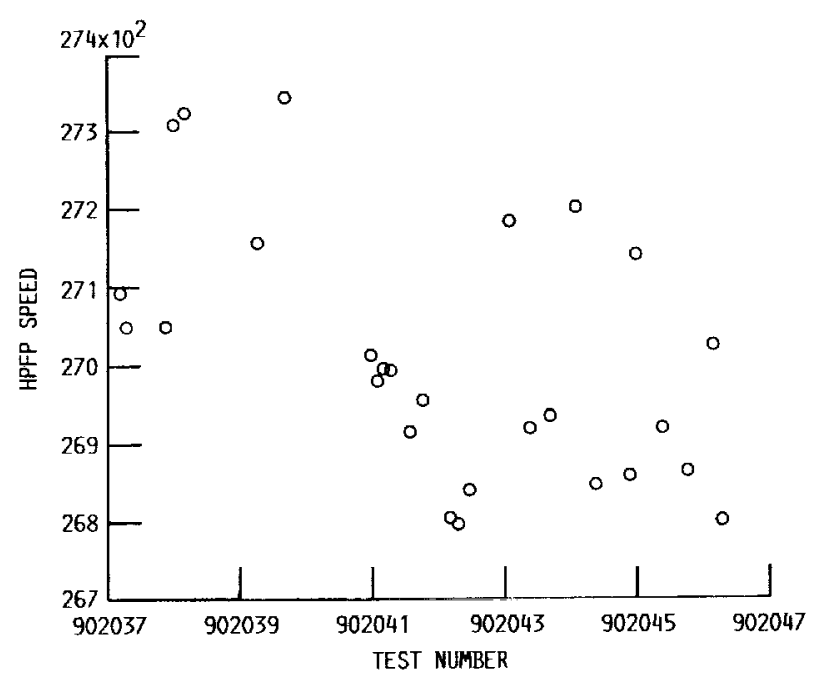

FIGURE 4. - MEASURED HPFP SPEED AT 65 PERCENT RPL.

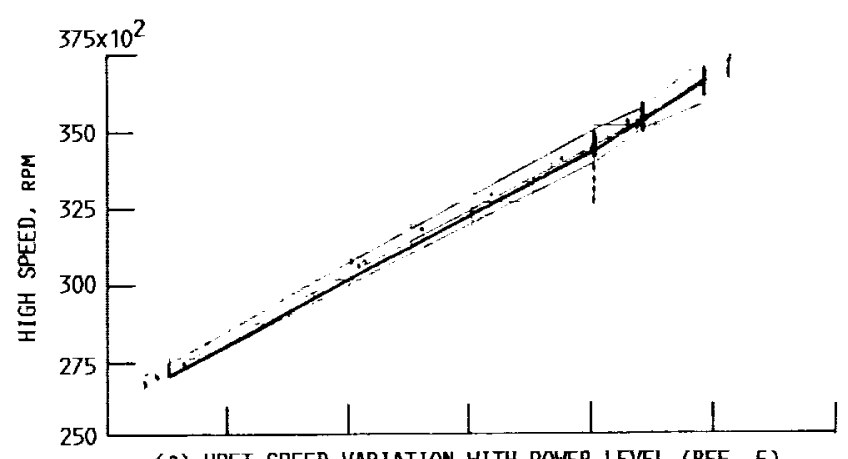

(a) HPFT SPEED VARIATION WITH PONER LEVEL (REF, 6).

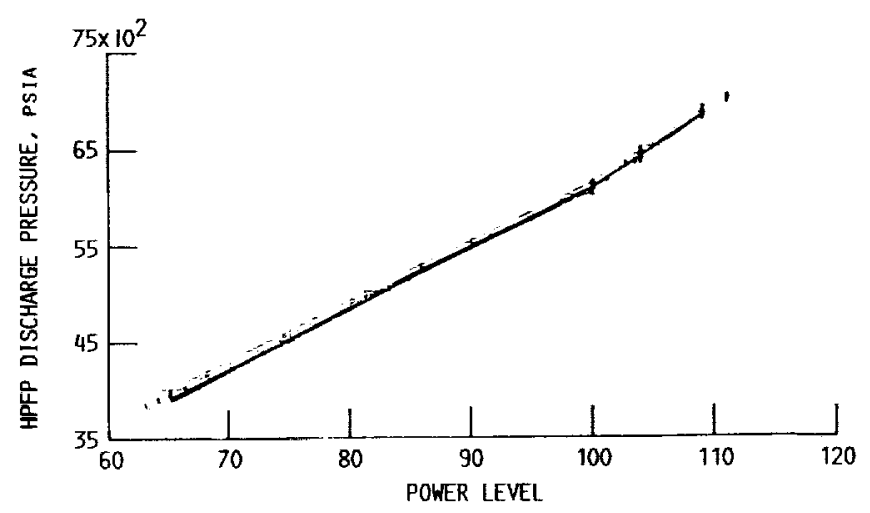

(b) HPFP DISCHARGE PRESSURE VARIATION WITH POWER LEVEL (REF, 6).

FIgURE 3. - ENGINE PERFORMANCE VARIATION. SAMPLE STANDARD DEVIATION, 2.00 SIGMA FRON THE SAMPLE AVERAGE.

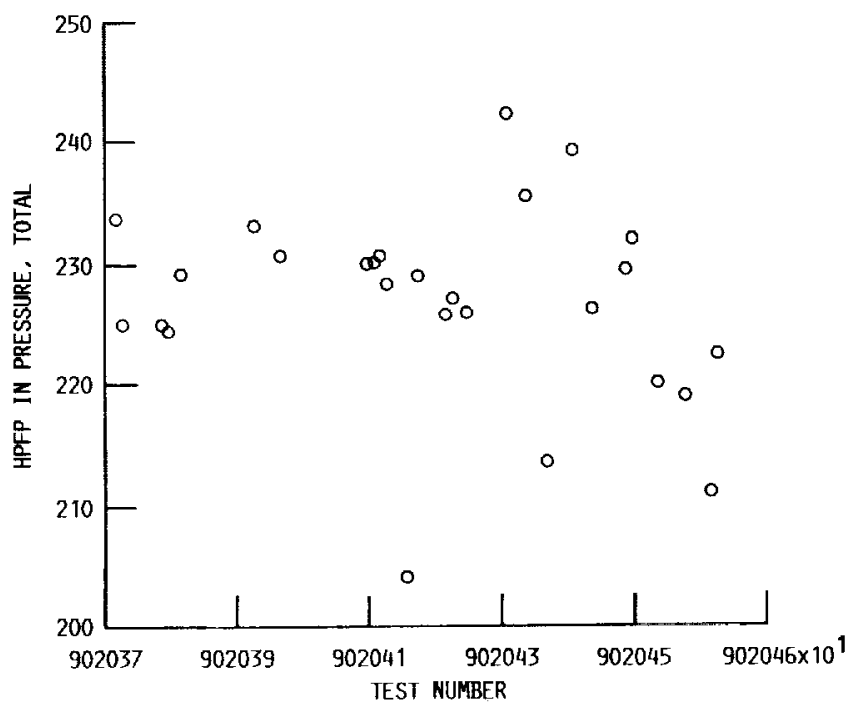

FIGURE 5. - MEASURED HPFP INLET PRESSURE AT 65 PERCENT RPL. 


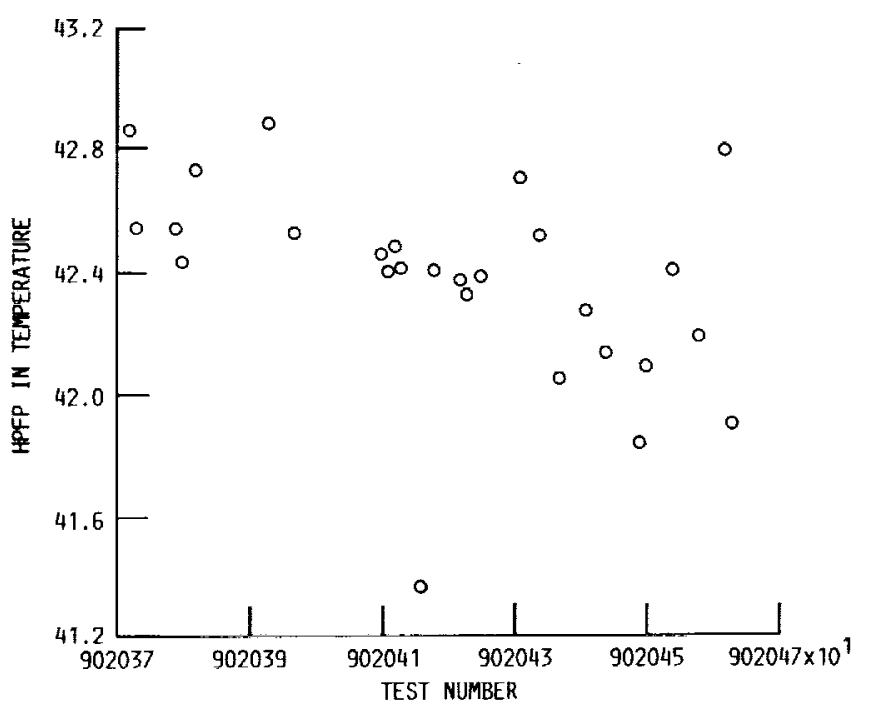

FIGURE 6. - MEASURED HPFP INLET TEMPERATURE AT 65 PER CENT RPL.

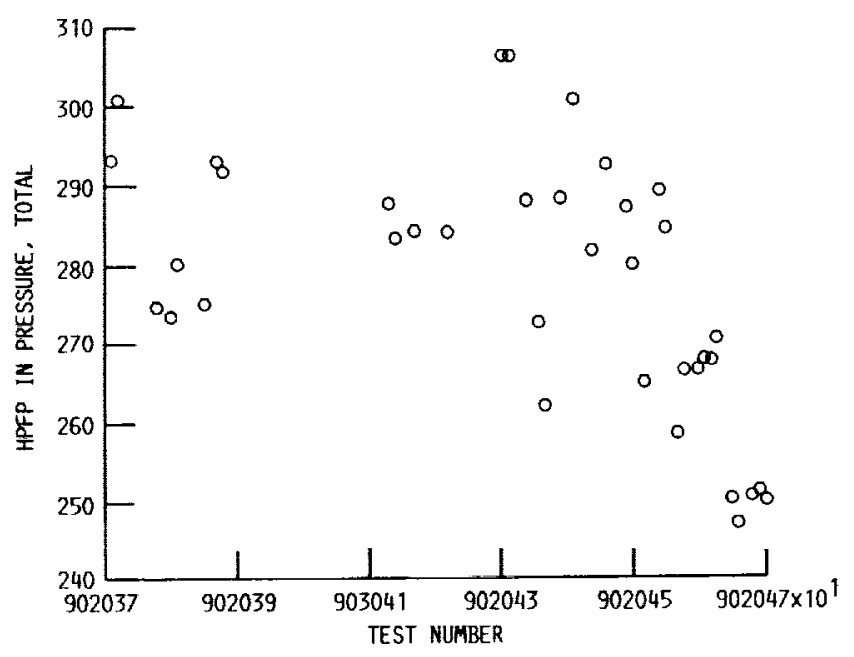

FIGURE 8. - MEASURED HPFP INLET PRESSUIRE AT 109 PERCENT RPL.

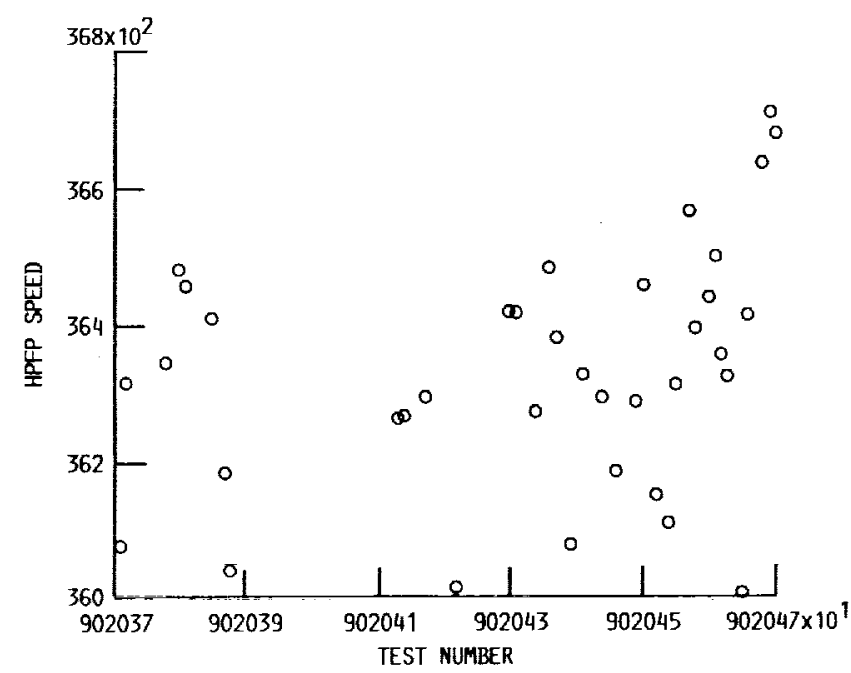

FIGURE 7. - MEASURED HPFL SPEED AT 109 PERCENT RPL.

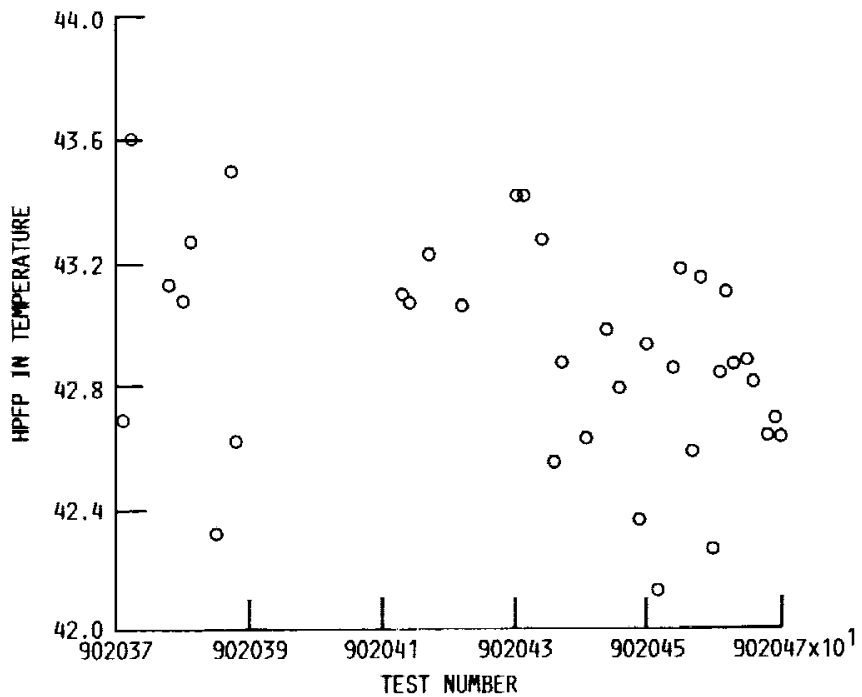

FIGURE 9. - MEASURED HPFP INLET TEMPERATURE AT 109 PERCENI RPL. 


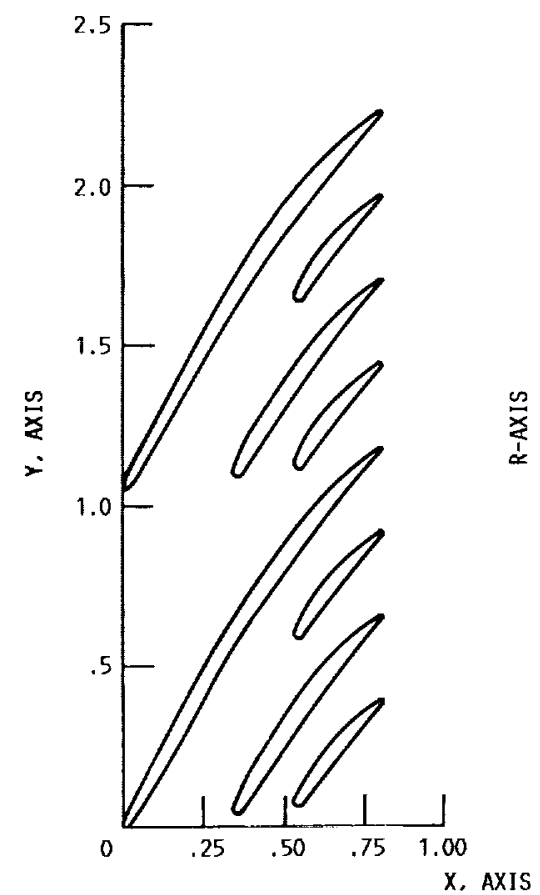

(a) TIP GEOMETRY.

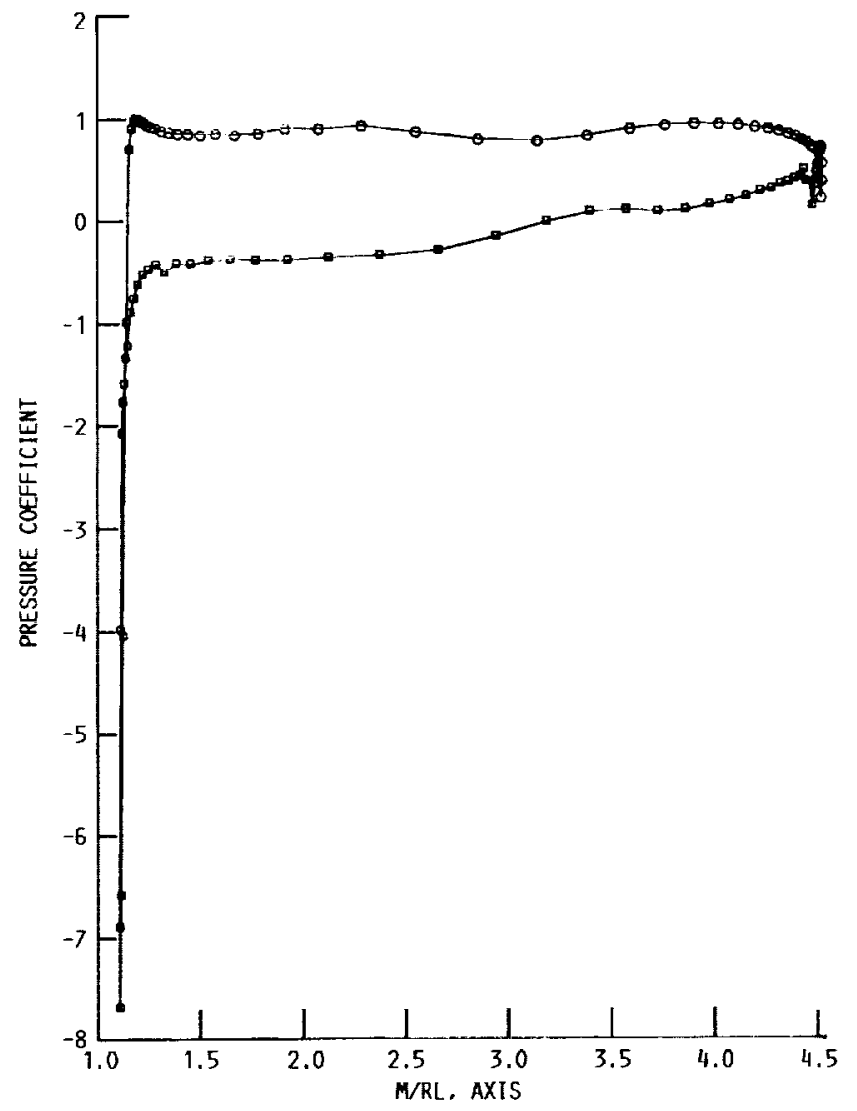

FIGURE 11. - hPFP BLADE 1 PRESSURE DISTRIBUtOR AT tHE TIP.

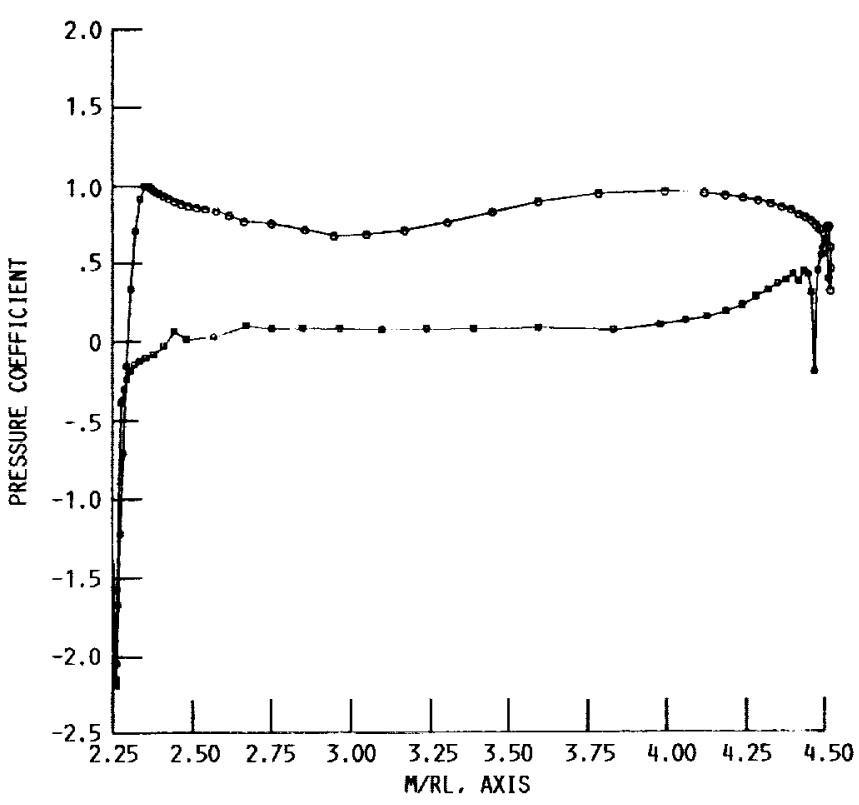

FIGURE 13. - BLADE 3. 

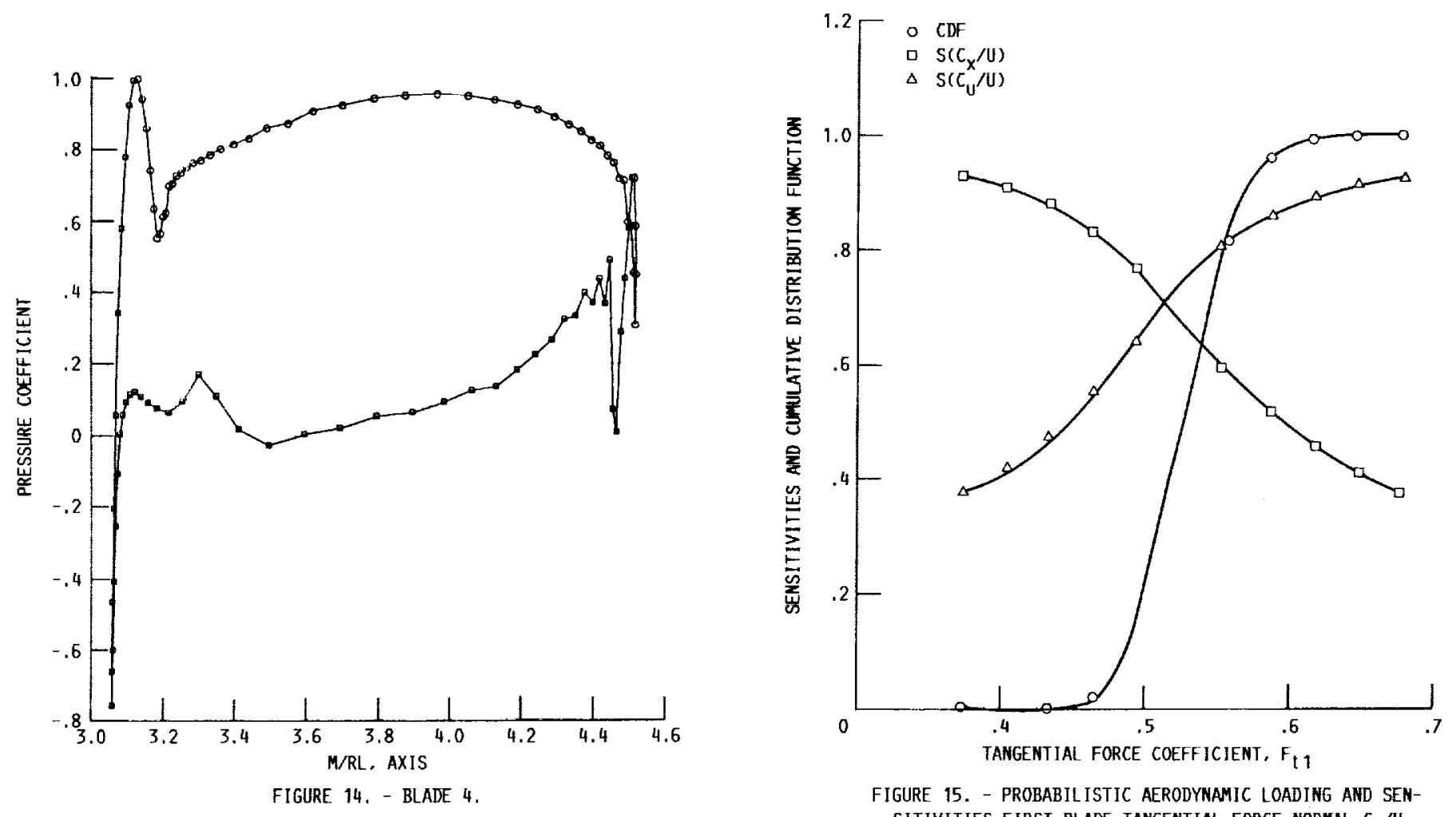

FIGURE 15. - PROBABILISTIC AERODYNAMIC LOADING AND SENSITIVITIES FIRST BLADE TANGENTIAL FORCE NORMAL $c_{\chi} N$. $C_{u}$ /U DISTRIBUTIONS WITH 10 PERCENT STANDARD DEVIATION. 


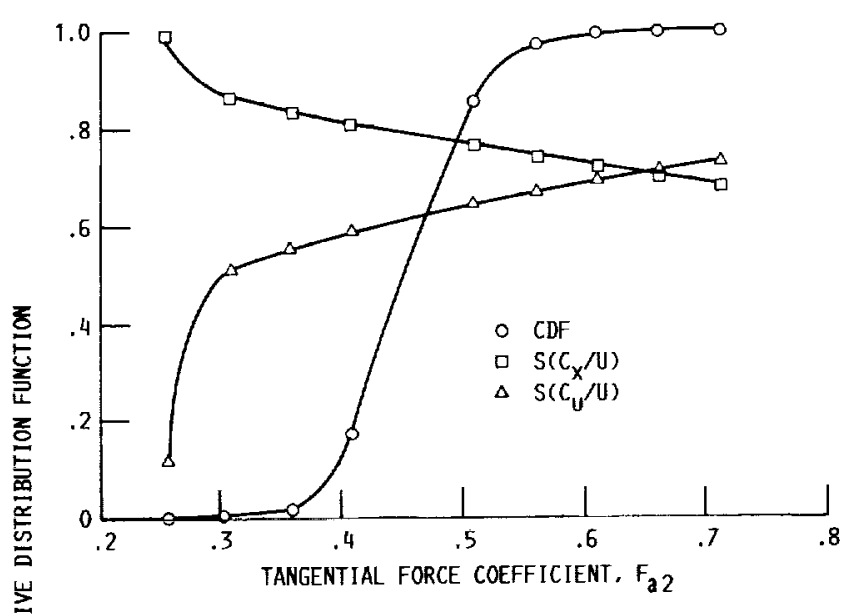

(a) TANGENTIAL FORCE COEFFICIENT: MEAN VALUE, 0.4610 ; STANDARD DEVIATION. 0.0506 .

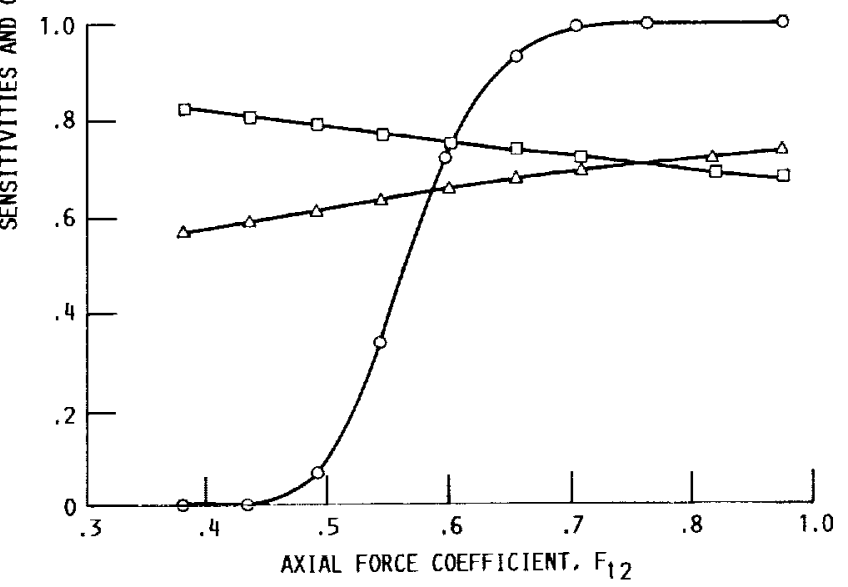

(b) AXIAL FORCE COEFFICIENT; MEAN Value, 0.5175; STANDARD DEVIATION, 0.0550 .

FIGURE 16. - PROBABILISTIC AERODYNAMIC LOADING AND SENSITIVITIES SECOND BLADE TANGENTIAL FORCE NORMAL $c_{x} / U, C_{u} / U$ DISTRIBUTIONS WITH 10 PERCENT STANDARD DEVIATION.

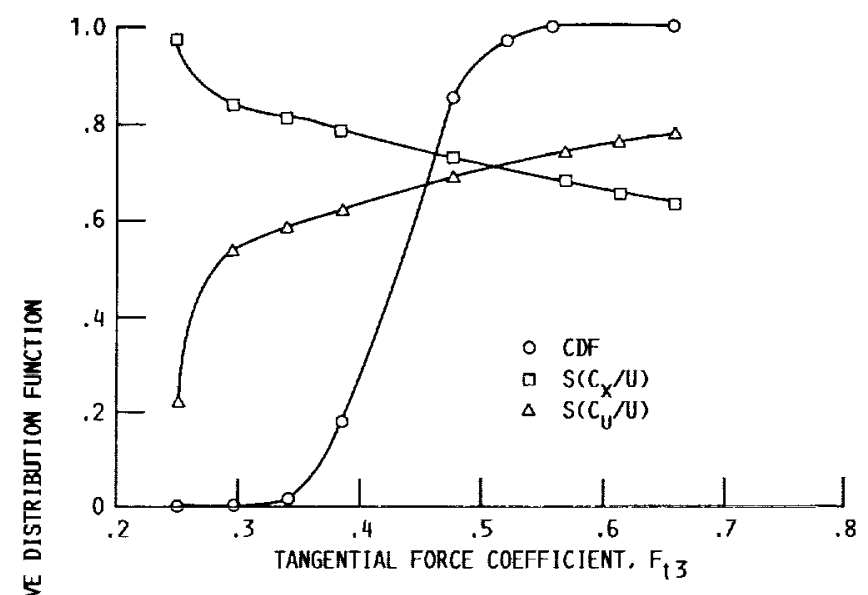

(a) TANGENTIAL FORCE COEFFICIENT; MEAN VALUE, 0.4320 ; STANDARD DEVIATION, 0.0454 .

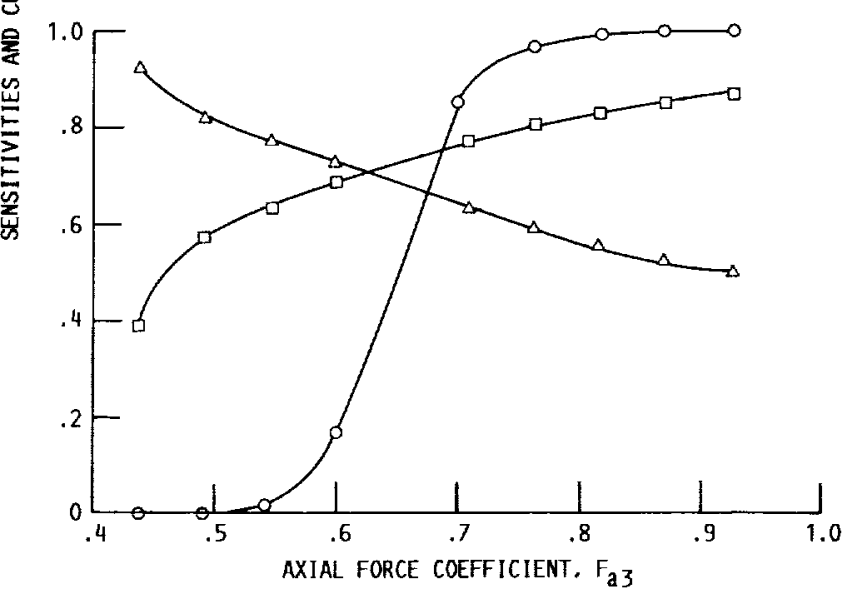

(b) AXIAL FORCE COEFFICIENT: MEAN VALUE, 0.6546; STANDARD DEVIATION, 0.0541 .

FIGURE 17. - PROBABILISTIC AERODYNAMIC LOADING AND SEN-

SITIVITIES THIRD BLADE TANGENTIAL FORCE NORMAL $C_{x} / \mathrm{U}$. $c_{U} / U$ DISTRIBUTIONS WITH 10 PERCENT STANDARD DEVIATIION. 


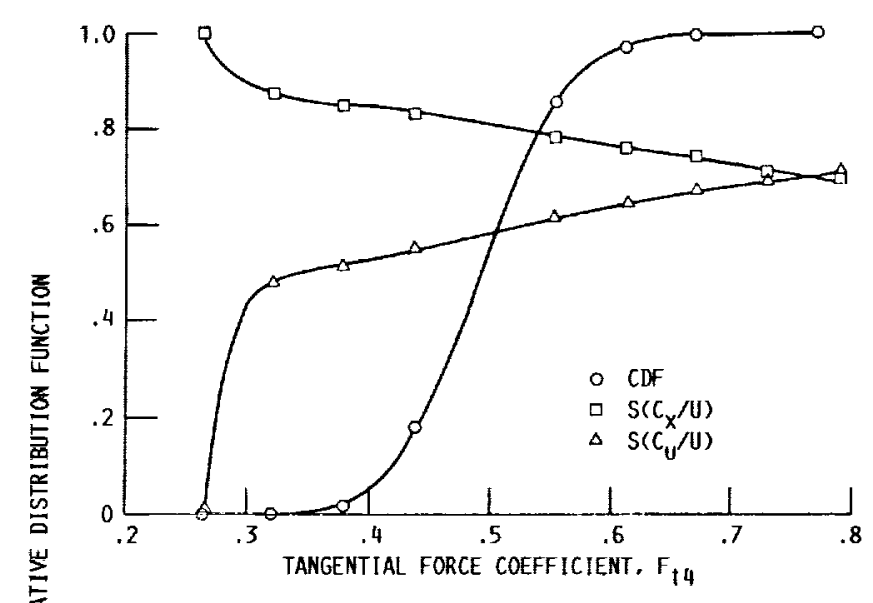

(a) TANGENTIAL FORCE COEFFICIENT: MEAN VALUE, 0.4985 ; STANDARD DEVIATION, 0.0584

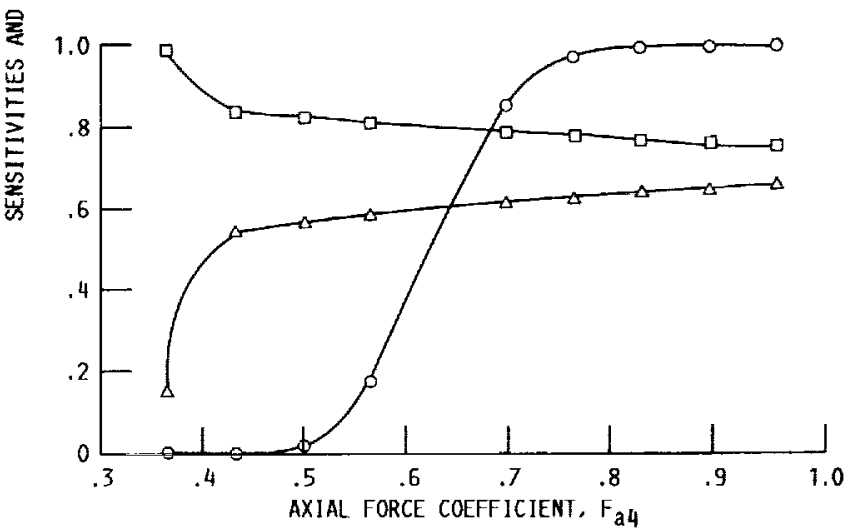

(b) AXIAL FORCE COEFFICIENT: MEAN VALUE, 0.63175; STAMDARD DEVIATION, 0.0663 .

FIGURE 18. - PROBABILISTIC AERODYNAMIC LOADING AND SENSITIVITIES FOURTH BLADE AXIAL FORCE NORMAL $c_{x} / U, c_{u} / U$ DISTRIBUTIONS WITH 10 PERCENT STANDARD DEVIATION.

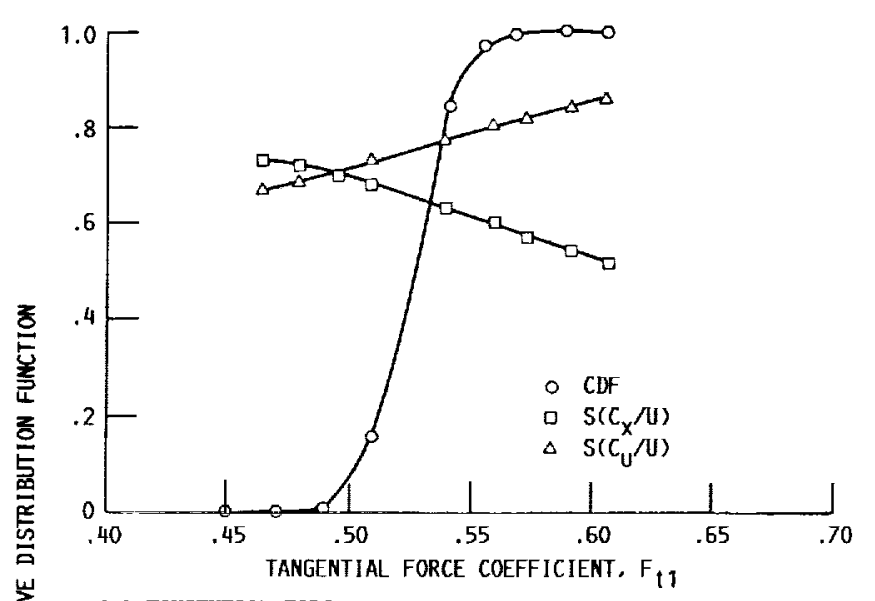

(a) TANGENTIAL FORCE COEFFICIENT: MEAN VALUE, 0.5275; STANDARD DEVIATION, 0.01595 .

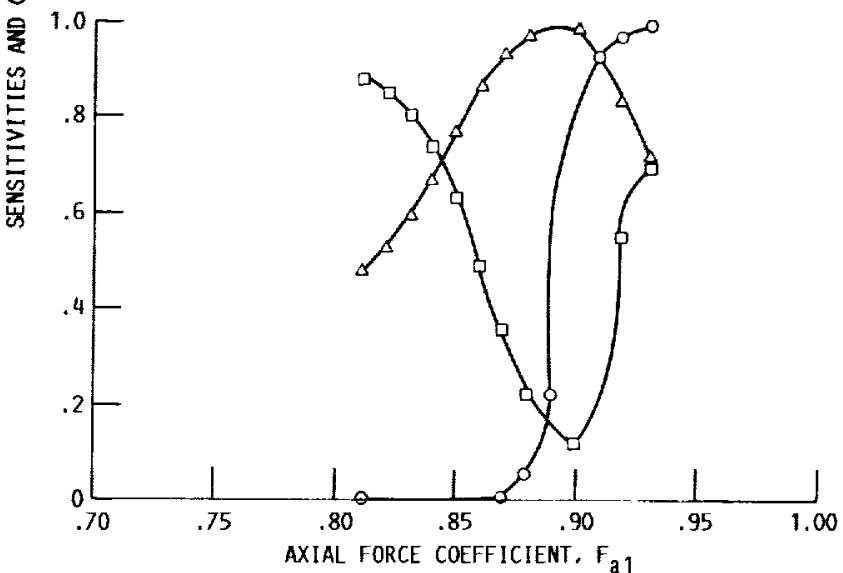

(b) AXIAL FORCE COEFFICIENT: MEAN VALUE, 0.8945; STANDARD DEVIATION, 0.0971 .

FIGURE 19. - PROBABILISTIC AERODYNAMIC LOADING AND SENSITIVITIES FIRST BLADE AXIAL FORCE LOG NORMAL $C_{x} / U$, $c_{u} / U$ DISTRIBUTIONS WITH 5 PERCENT STANDARD DEVIATION. 


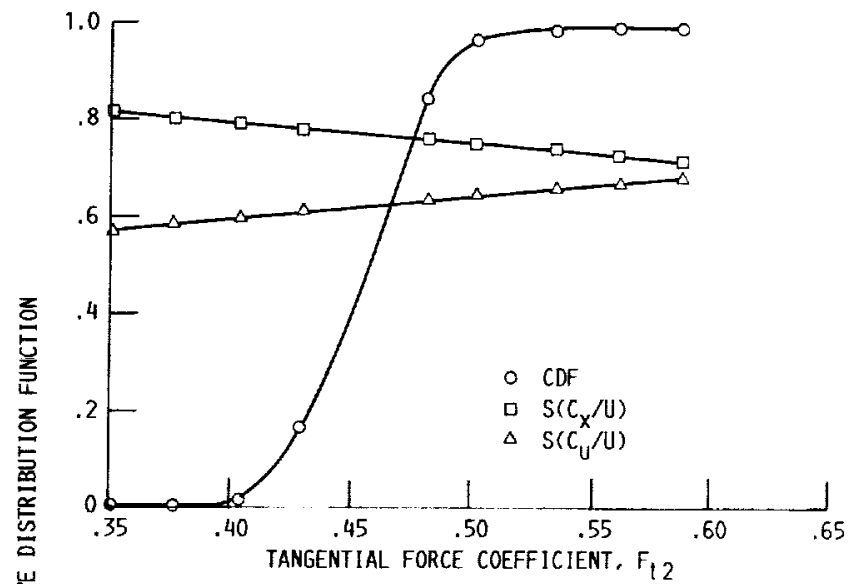

(a) TANGENTIAL FORCE COEFFICIENT; MEAN VALLIE, 0.4565 : STANDARD DEVIATION, 0.0263 .

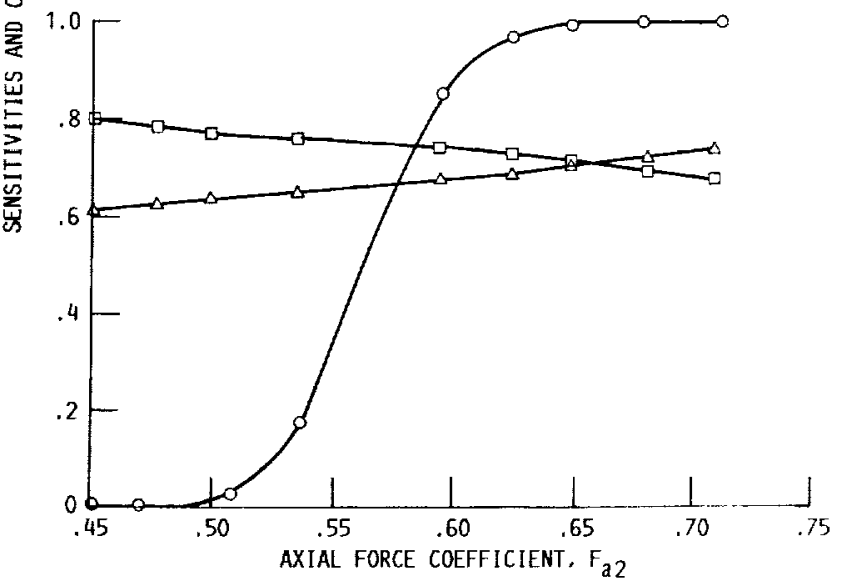

(b) AXIAL FORCE COEFFICIENT; MEAN VALUE, 0.5666; STANDARD DEVIATION, 0.0292 .

FIGURE 20, - PROBABILISTIC AERODYNAMIC LOADING AND SENSITIVITIES SECOND BLADE AXIAL FORCE LOG NORMAL $c_{x}, U, c_{u} / U$ DISTRIBUTIONS WITH 5 PERCENT STANDARD DEVIATION.

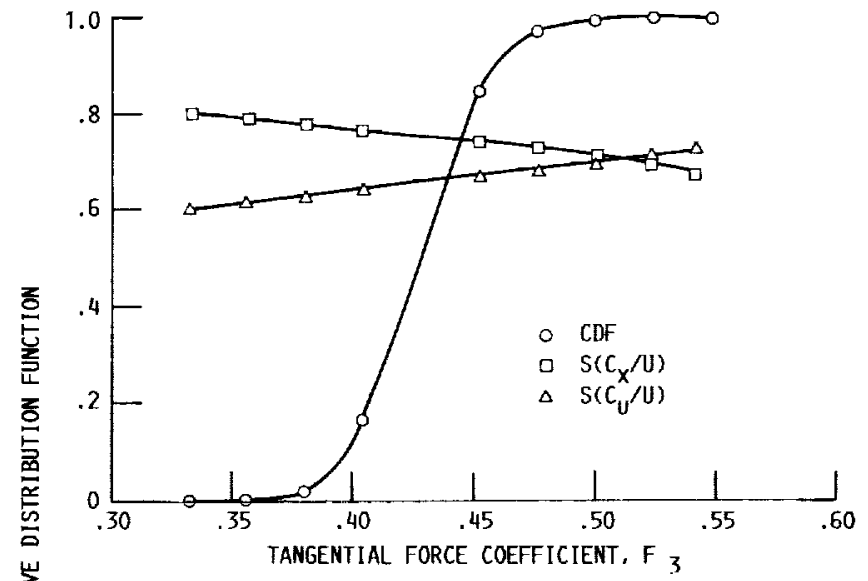

(a) TANGENTIAL FORCE COEFFICIENT; MEAN VALUE, 0.4275 ; STANDARD DEVIATION, 0.02375 .

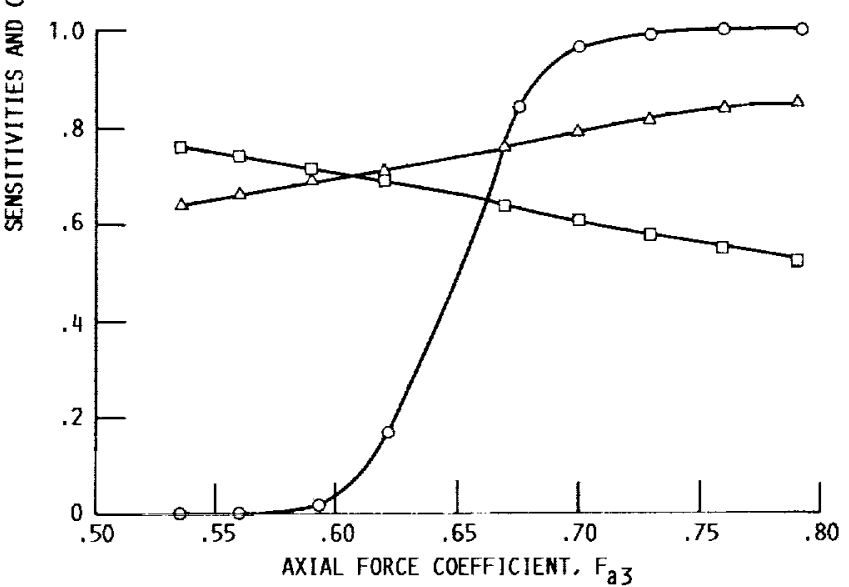

(b) AXIAL FORCE COEFFICIENT; MEAN VALUE, 0.65; STANDARD DEVIATION, 0.0283

FIGURE 21. - PROBABILIISTIC AERODYNAMIC LOADING AND SENSITIVITIES THIRD BLADE AXIAL FORCE LOG NORMAL $C_{x} / \mathrm{N}$. $C_{u} / U$ DISTRIBUTIONS WITH 5 PERCENT SIANDARD DEVIATION. 


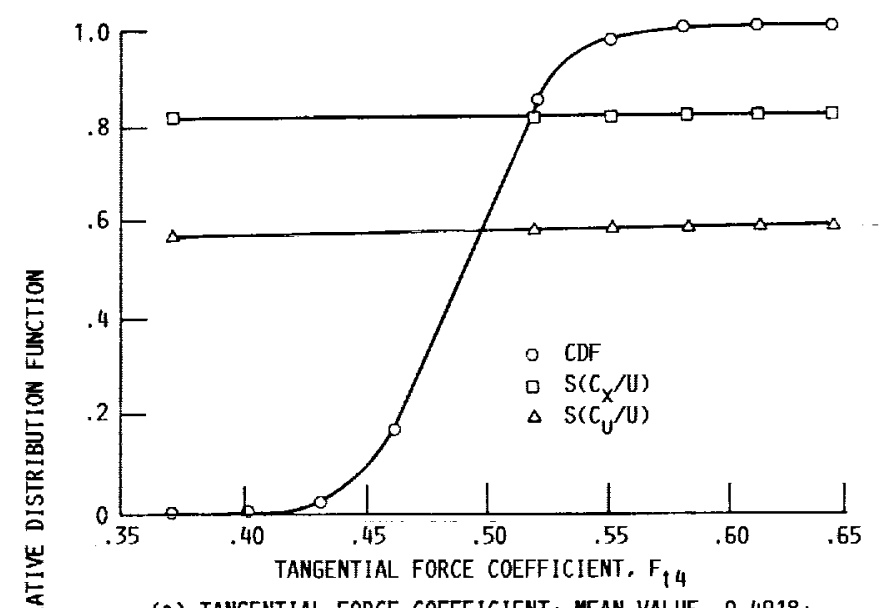

(a) TANGENTIAL FORCE COEFFICIENT: MEAN VALUE, 0.4918 ; STANDARD DEVIAIION, 0.0303 .

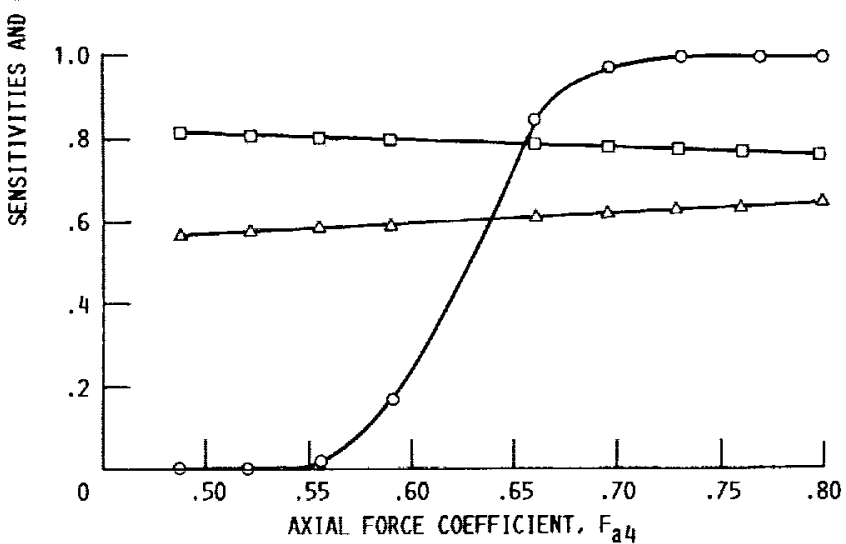

(b) AXIAL FORCE COEFFICIENT: MEAN VALUE, 0.6255; STANDARD DEVIATION, 0.0346 .

FIGURE 22. - PROBABILISTIC AERODYNAMIC LOADING AND SENSITIVITIES FOURTH BLADE AXIAL FORCE LOG NORMAL $c_{x} / \mathrm{l}, c_{u} / U$ DISTRIBUTIONS WITH 5 PERCENT STANDARD DEVIATION.

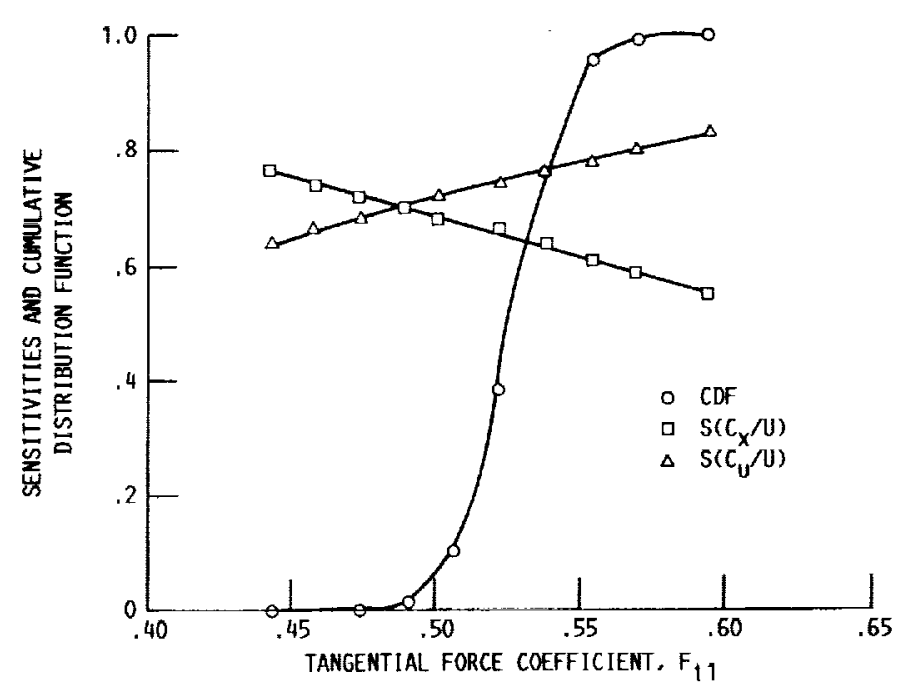

FIGURE 23. - PROBABILISTIC AERODYNAMIC LOADING AND SENSITIVITIES FIRST BLADE TANGENTIAL FORCE NORMAL $c_{x} / U, c_{u} / U$ DISTRIBUTIONS WITH 5 PERCENT STANDARD DEVIATION. 


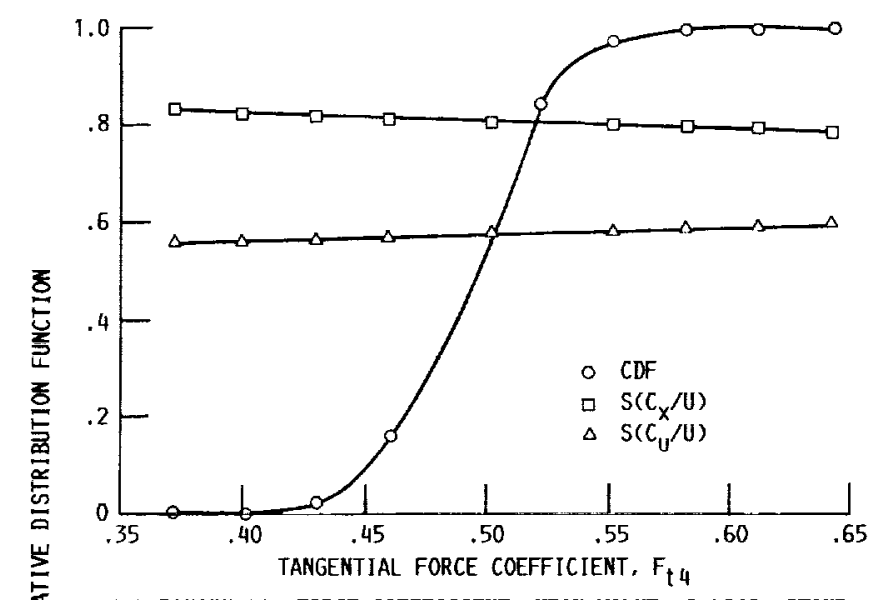

(a) TANGENTIAL FORCE COEFFICIENT: MEAN VALUE, 0.4918: STANDARD DEVIATION, 0.0303 .

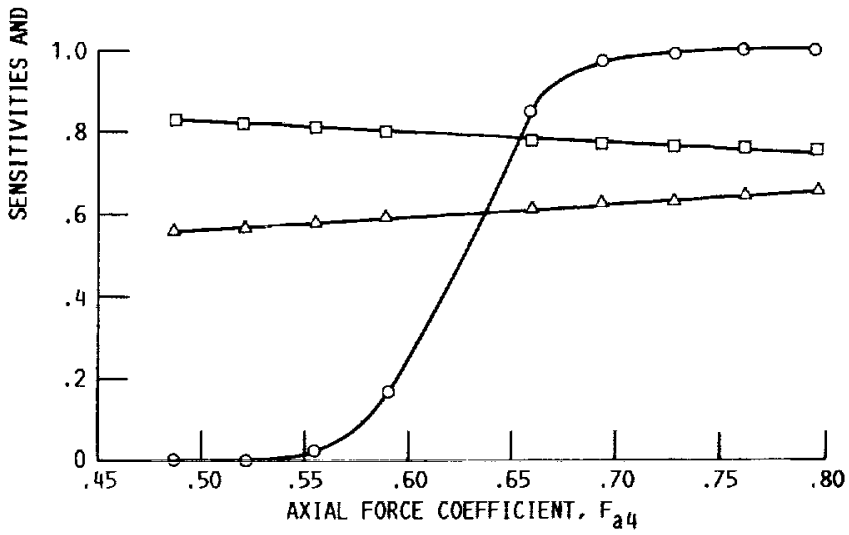

(b) AXIAL FORCE COEFFICIENT; MEAN VALUE, 0.6255; STANDARD DEVIATION, 0.0346 .

FIGURE 24. - PROBABILISTIC AERODYNAMIC LOADING AND SENSITIVITIES FOURTH BLADE AXIAL. FORCE NORMAL $c_{X} / U, C_{U} / U$ DISTRIBUTIONS WITH 5 PERCENT STANDARD DEVIATIOON.

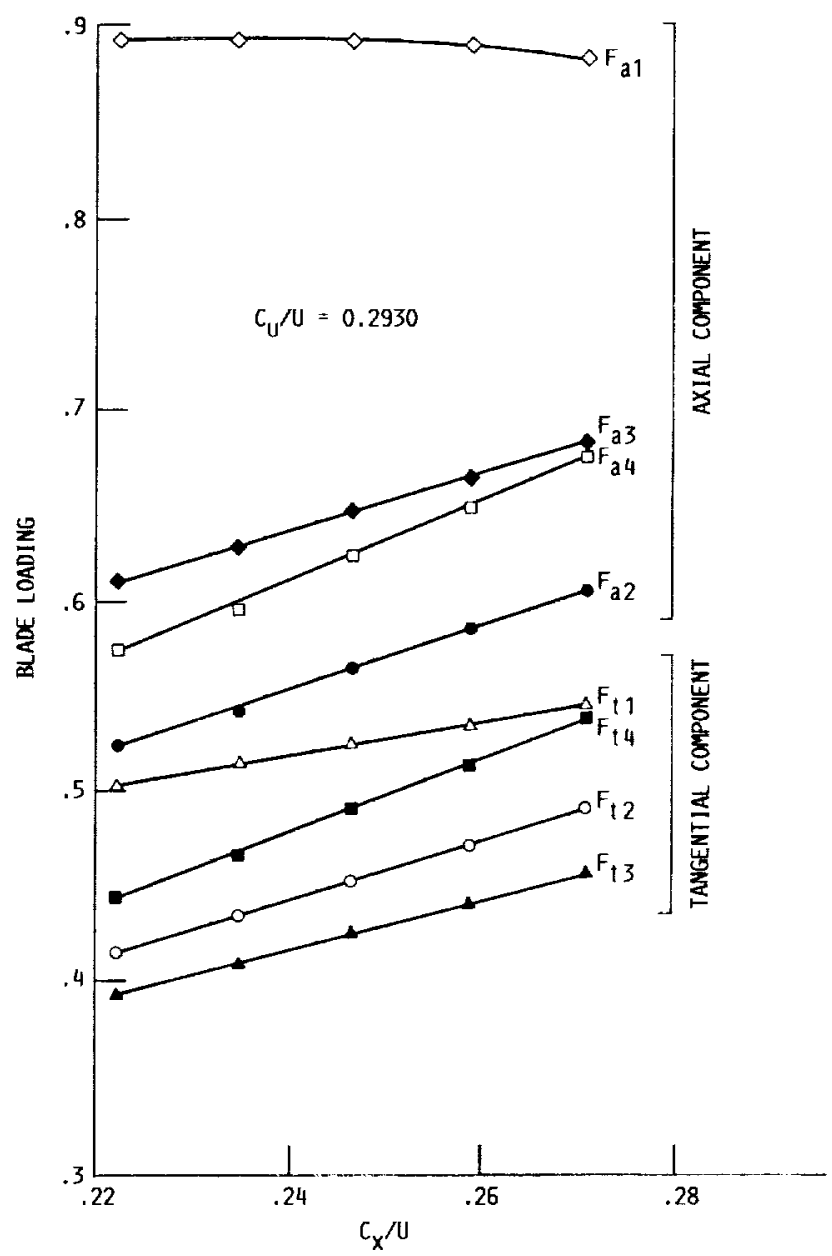

FIGURE 25. - VARIATION OF BLADE LOADING WITH FLOW COEFFICIENT. 


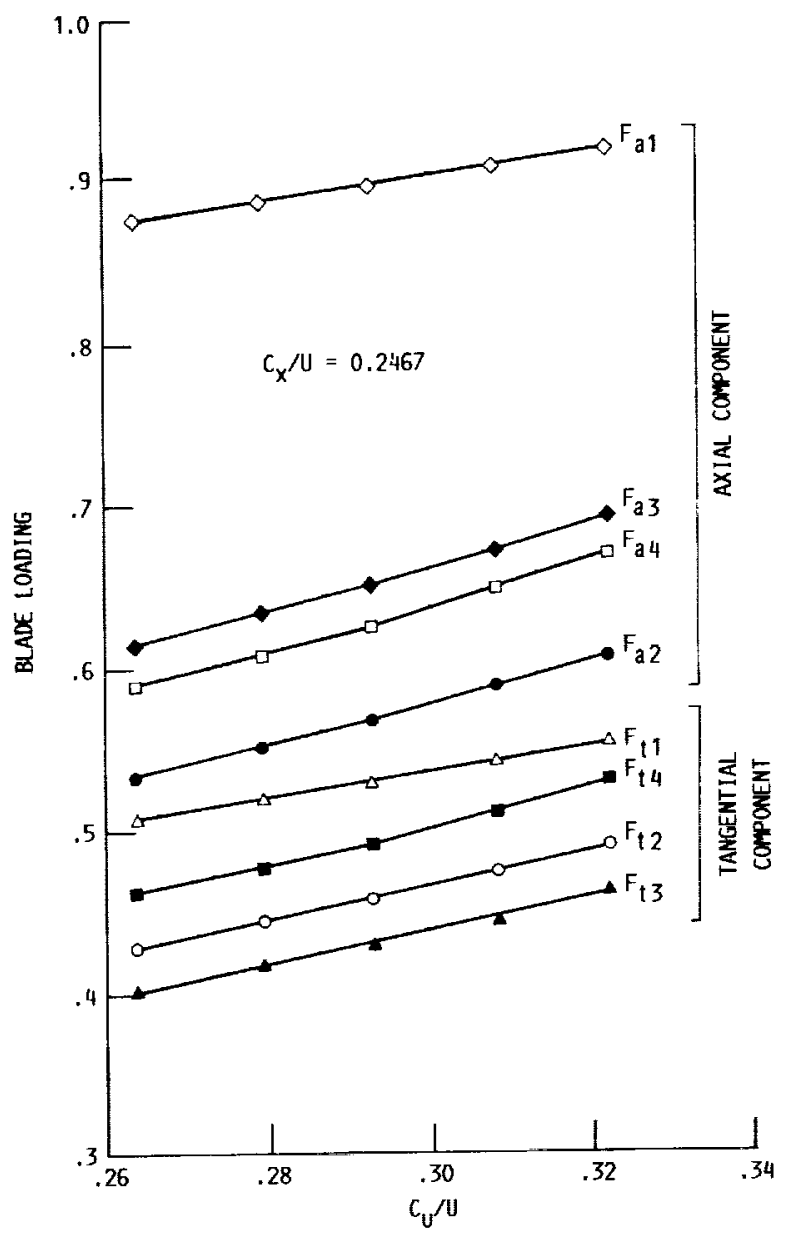

FIGURE 26. - VARIATION OF BLADE LOADING WITH THE PRESWIRL. 


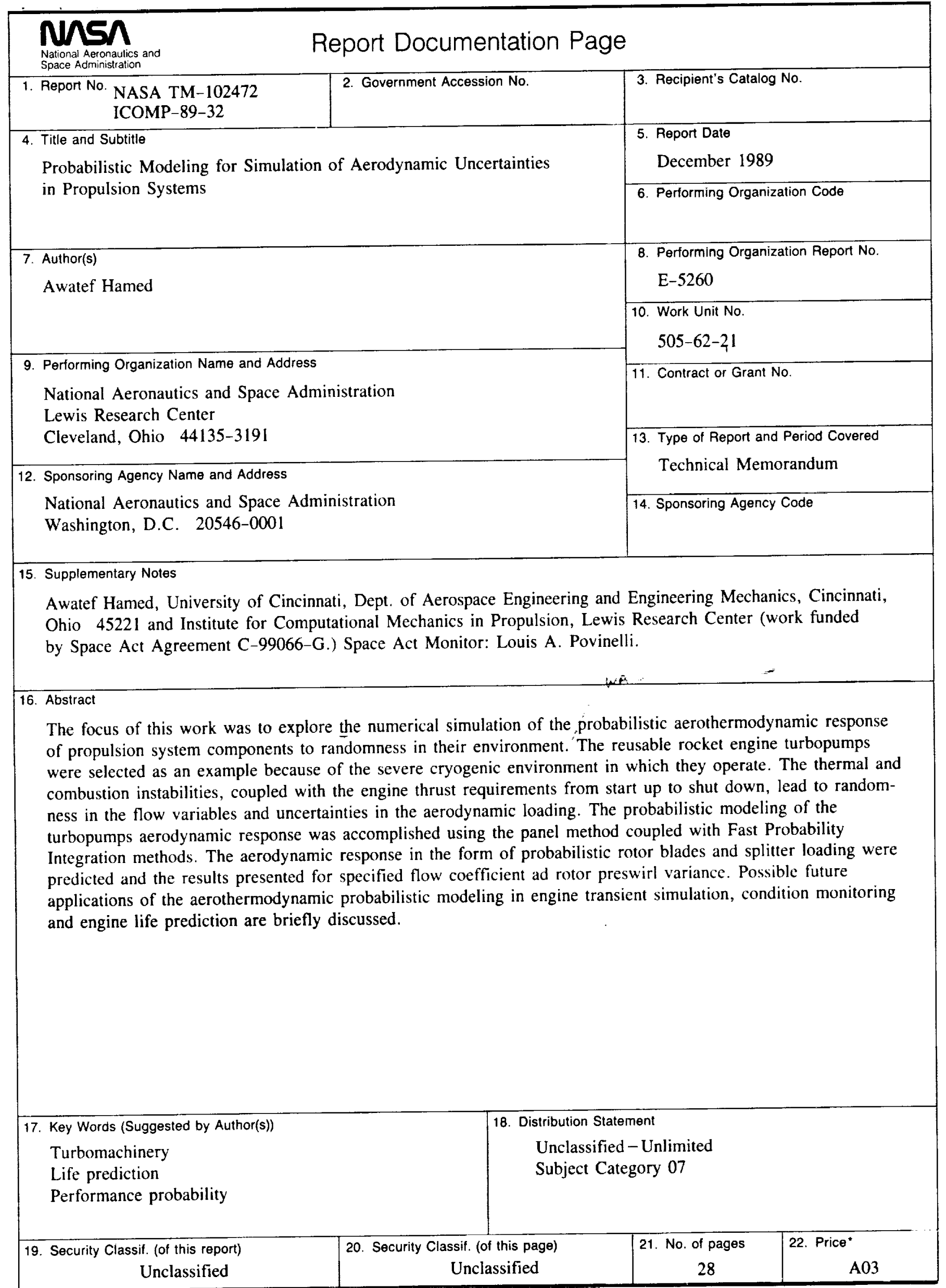


